\title{
Amigos do peso: intervenção multiprofissional em grupo
}

\author{
Irene da Silva Araújo Gonçalves, Naisy Maria Gonçalves Milagres, Adriana Vidigal Reis
}

\begin{abstract}
Resumo
A prevalência de sobrepeso e obesidade vem aumentando mundialmente, sendo considerada um importante problema de saúde pública. Este novo panorama sinaliza um processo de transição epidemiológica e nutricional que deve ser devidamente valorizado. Frente a esse novo padrão epidemiológico, profissionais do NASF do município de Piranga/MG, implantaram um grupo de apoio, propondo uma modalidade de assistência integral ao usuário com excesso de peso. $\mathrm{O}$ grupo de apoio batizado de "Amigos do Peso" tem caráter multiprofissional, sendo composto por nutricionista, fisioterapeuta e psicóloga. Orientar mudanças nos hábitos alimentares e no estilo de vida; prevenir doenças crônicas não transmissíveis e criar um espaço terapêutico de convivência, troca de informações e experiências. A partir do acúmulo de encaminhamentos ambulatoriais destinados ao serviço de nutrição, a nutricionista convidou a psicóloga e a fisioterapeuta para montarem uma metodologia de trabalho em grupo. À nutricionista cabe promover a reeducação alimentar e incentivar a autonomia na decisão da escolha de práticas alimentares saudáveis; à fisioterapeuta conscientizar os integrantes da importância da atividade física e à psicóloga promover um espaço terapêutico de partilha e trocas de experiência. Com número máximo de 20 integrantes exclusivamente do sexo feminino e com IMC acima de $30 \mathrm{KG} / \mathrm{m} 2$; o grupo se reúne em encontros semanais, em ciclos semestrais. As três profissionais alternam suas atividades semanalmente, o encontro de abertura e encerramento é feito em conjunto. $\mathrm{O}$ acompanhamento nutricional inicia com o atendimento individual e a partir daí todos os aspectos tratados na conduta individual passam a ser retomados coletivamente, focando a reeducação alimentar. Técnicas de motivação propiciam momentos de descontração e interação, fornecendo subsídios para a adesão e participação das integrantes nas temáticas desenvolvidas. Inicialmente as participantes mostram-se dispostas a mudar a dieta, o comportamento alimentar e o estilo de vida. Com o tempo observa-se queda na frequência e na motivação, embora cerca da metade das participantes alcancem o objetivo proposto. Adotou-se a estratégia de doação de $1 \mathrm{Kg}$ de alimento para cada ganho de peso ou falta nos encontros, a fim de firmar o compromisso assumido. Mesmo que individualmente o resultado não seja tão expressivo em peso perdido, observa-se a cada ciclo melhora do estilo de vida e bem estar geral das participantes. As estratégias utilizadas possibilitam uma reflexão a partir da realidade das participantes, desencadeando um processo de reflexão e conscientização do estilo de vida mais saudável e mudanças do hábito alimentar. O grupo de apoio por ser de autoajuda e multiprofissional possibilita ao atendimento um dinamismo peculiar, que não ocorre no atendimento individualizado. Encontros semanais com propostas baseadas em uma modalidade terapêutica mais abrangente possibilitam ao usuário uma forma alternativa e motivadora para a busca de qualidade de vida. No entanto, sabe-se que o comportamento humano, em sentido amplo, está sob o controle da vontade pessoal e, portanto, a mudança de atitude somente ocorre quando o usuário esforça-se para isso.
\end{abstract}

Descritores: Apoio, Reeducação alimentar, Equipe multiprofissional. 